\title{
COMPARTMENT AND FAÇADE LARGE SCALE TESTS: BEHAVIOR COMPARISON OF DIFFERENT INSULATING MATERIALS IN CASE OF FIRE
}

\author{
Elsa Pastor ${ }^{\mathrm{a}}$, Beatriu Corberó ${ }^{\mathrm{a}}$, Oriol Rios ${ }^{\mathrm{a}}$, María Pilar Giraldo ${ }^{\mathrm{b}}$, Laia Haurie ${ }^{\mathrm{c}}$, Ana \\ Lacasta $^{c}$, Eva Cuerva ${ }^{\mathrm{d}}$, Eulalia Planas ${ }^{\mathrm{a}}$ \\ ${ }^{a}$ Centre for Technological Risk Studies (CERTEC). Department of Chemical Engineering. Universitat Politècnica de \\ Catalunya BarcelonaTech. Diagonal 647, 08028 Barcelona, Catalonia, Spain \\ ${ }^{\mathrm{b}}$ Catalan Institute of Wood (INCAFUST - CTFC), Ctr.Sant Llorenç Km 2, Solsona, Catalonia, Spain \\ ${ }^{c}$ Barcelona School of Building Construction, Universitat Politècnica de Catalunya BarcelonaTech, Avda Doctor \\ Marañon 44, 08028 Barcelona, Catalonia, Spain \\ ${ }^{\mathrm{d}}$ Department of construction. Universitat Politècnica de Catalunya BarcelonaTech. Diagonal 647, 08028 Barcelona, \\ Catalonia, Spain
}

\begin{abstract}
Fire safety community is currently concerned about the response of some widely used insulating materials in case of fire, due to the fact that existing regulations do not show how these materials behave in real conditions, which in some applications may be indeed critical. Within this context, several institutions have recently carried out large-scale tests with the aim of testing such insulator's contribution to fire growth. In this paper we present a set of large scale tests of compartment and façade fires involving materials and configurations of different nature. Our experiments provided evidence that mineral wool insulator preserves its properties in case of fire, whilst other polymerictype insulators contribute to fire growth in conditions close to the ones present in real fires.
\end{abstract}

Keywords: Room corner test, ventilated façades, mineral wool, polyisocyanurate, expanded polystyrene, polyurethane.

\section{INTRODUCTION}

Urban fires (in homes, factories, warehouses, parking lots, etc.) represent roughly the $80 \%$ of the fire brigades services in Spain, and cause very severe damage at human, economic and environmental levels. In Europe, between 2.0 and 2.5 million of fires are reported every year, provoking more than 20,000 deaths and between 250,000 - 500,000 fire injuries per year (Netherlands Institute for Safety Nibra, 2009). Costs due to losses from fires amount tens of billions globally and have been roughly estimated as $1 \%$ of global GDP per annum (The Geneva Association, 2014).

In this context, existing fire regulations and codes have not evolved at the same pace as the complexity of the current fire scenarios and cannot be considered benchmarks effective enough to ensure fire safety. This is mainly due to its succinctness and low specificity in certain systems and construction solutions as well as due to the adoption of materials' classification criteria (i.e. Euroclasses) based on small-scale tests, which may fail to reproduce certain fire behaviour features under real conditions.

Façade fires are one of the scenarios in which the above mentioned drawbacks are more evident. Façades are one of the fastest pathways for the fire to spread in buildings. In this part of the building, several factors favouring fire growth converge, being $i$ ) the unlimited supply of oxygen due to direct contact with fresh air and ii) the verticality of the surface which facilitates the attraction of the flame towards the façade (through the so-called Coanda effect) the most significant. Different situations may cause a façade fire, but the most common and dangerous one is the propagation of a fire that has been originated inside the building (Giraldo et al., 2013).

The use of ventilated facades (Fig. 1) has grown significantly in recent years due to its technical and aesthetical value, as this configuration has a very good hygrothermal and acoustic behaviour; 
particularly, its main advantages are energy efficiency and thermal comfort. By contrast, the risk of fire propagation in this type of façades is extremely high due to the "chimney effect" if fire barriers are not installed, which it is rather often the case.

Another façade configuration whose use has also been recently widened is the externally insulated facade (see Fig. 1), also called External Insulation Composite System (ETICS). This system is designed specifically to improve the energy efficiency of buildings; however, concerning its response to fire, it presents major concerns due to the fact that most of the materials used in its insulation layer are combustible and can contribute significantly to the growth and spread of the fire along the façade.
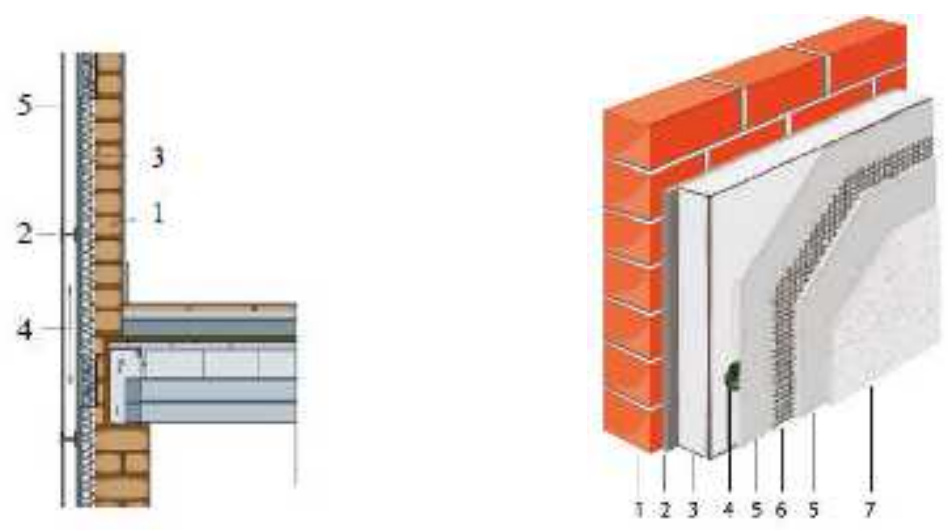

Fig. 1. (left) Elements of a ventilated façade: 1- support, 2- substructure, 3- insulation, 4- air chamber, 5cladding; (right) elements of an ETICS system: 1- wall, 2- adhesive, 3- insulation layer, 4- anchors, 5- base coat, 6- reinforcement mesh, 7- finishing layer (Adapted from EAE, 2015 and Giraldo et al. 2013)

The thermal insulation layers are also largely used inside buildings; nevertheless the criteria for materials classification according to the Euroclasses (89/106/CEE 2000/147/CE and 2003/632/CE) do not consider large scale tests to assess the behaviour of products in conditions and configurations similar to that of its final use. Therefore, the current classification based on small-scale laboratory tests may be in some cases not appropriate to represent real fire hazards (European Commission, 2003). However, several international (ISO) and European (CEN) standards for larger scale testing already exist and can be used to test products' performance in quasi-real conditions. This is the case, for instance, of the Room Corner Tests (RCT) detailed in the European standard EN 14390:2007 and ISO 9705, which emulates a fire under well-ventilated conditions in a corner of a small room with a single open doorway, or the ISO 13785-2:2002 for determining the reaction to fire of materials and construction of façades claddings, among others. Nevertheless, it is fully accepted within the fire scientific and technical community that more research efforts are needed to develop and harmonize larger scale tests, which can cover complex real fire scenarios.

In this paper a set of large scale tests of compartment and façade fires involving materials and configurations of different nature are presented. We include five compartments and four façades experiments with the aim of testing insulator's contribution to fire growth. Preliminary results in terms of the dynamic temperature response are briefly showed and analysed for every tested specimen and some concluding remarks concerning insulators performance are announced.

\section{MATERIALS AND METHODS}

\subsection{Compartment tests}

The experimental tests comprised five compartments; three of them (RCT) were performed according to the above mentioned standard EN 14390:2007 and the other two (PSW), the so-called "Sandwich Panel Tests", followed the main procedures detailed at the ISO 13784-1:2014 and the ISO 13784-2:2014.

The insulation materials under study in the RCT experiments were mineral wool (MW), polyisocyanurate (PIR) and expanded polystyrene (EPS). In the PSW experiments, mineral wool 
and polyurethane (PUR) were tested as insulators within sandwich panels. It is noteworthy to mention that materials from different natures -polymeric and mineral- were compared.

The five compartments were identical in size and shape. They were $2.4 \mathrm{~m}$ long and wide and $3.6 \mathrm{~m}$ high (Fig. 2) with a front opening of $0.8 \mathrm{~m}$-width and $2 \mathrm{~m}$-height.

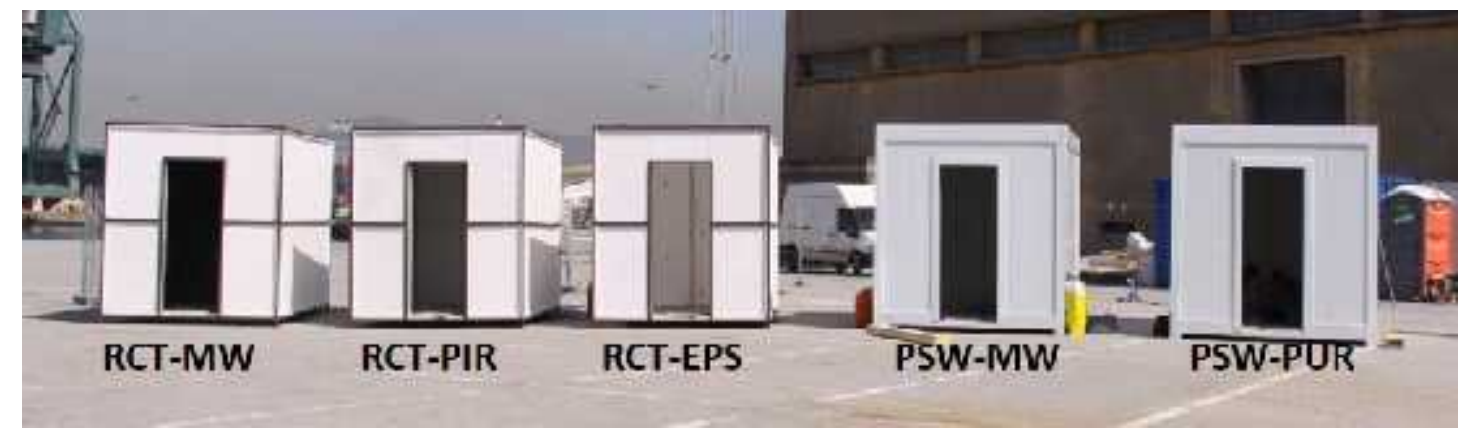

Fig. 2. Compartments of the RCT and PSW tests

The ignition source was a $170 \mathrm{~mm}$-long and wide and $200 \mathrm{~mm}$-high propane burner located at the right corner at the back of each compartment. The burner supplied a heat flux of $100 \mathrm{~kW}$ during the first 10 minutes of the tests, and $300 \mathrm{~kW}$ for the following 10 minutes (a test was considered completed 20 minutes after ignition). Monitoring systems recorded data during the whole duration of the experiments. When tests were finished, fire brigades would extinguish the fire by means of water hoses.

The experiments were filmed using a standard video camera (visual spectrum, SONY® Handycam $H D R$ J10) and an infrared (IR) camera, AGEMA® 570 Pro, operating in the $7.5-13 \mathrm{~m}$ range, equipped with a frame grabber storing sequences of 240x320-pixel images. Both cameras were located in front of the opened side of the compartments, capturing the evolution of the tests all together. A thermocouples tree was placed in the centre of each compartment. For the RCT fires, each tree contained two K-type thermocouples, located at $0.4 \mathrm{~m}$ and $2.2 \mathrm{~m}$ above the ground level. For the PSW tests, four K-type thermocouples were located at the tree (at 0.4, 1.4, 1.8 and $2.2 \mathrm{~m}$ ). The data loggers used to register temperatures (Onset HOBO ${ }^{\circledR}$ loggers) were set to record temperatures at $1-\mathrm{Hz}$ frequency. Finally, a portable weather station was placed close to the experimental site to monitor the main meteorological variables, such as temperature, relative humidity and wind speed and direction.

\subsection{Façades tests}

The experimental tests comprised four façades and they were undertaken following the main procedures explained at the British standard BS 8414. The configurations of the four models were as follows: two of them represented ETICS façades, being the insulator EPS in one of them and MW in the other. The second pair of façades were ventilated (VENT), being in these cases PUR and MW the selected insulators. Table 1 shows the main layers making up the façade modules tested.

Table 1. Multilayer façades characteristics

\begin{tabular}{|l|l|}
\hline ETICS façades & VENTILATED façades \\
\hline Support (concrete) & Support (concrete) \\
Insulation, 120 mm (EPS / MW) & Insulation, $100 \mathrm{~mm}$ (PUR / MW) \\
External cladding (mortar with siloxane) & $\begin{array}{l}\text { Air chamber, } 40 \mathrm{~mm} \\
\text { External cladding (phenolic plate for the PUR } \\
\text { insulated façade / MW plate for the MW-ins. façade) }\end{array}$ \\
\hline
\end{tabular}

The four façades were identical in terms of dimensions. They were $2.8 \mathrm{~m}$ wide and $8 \mathrm{~m}$ high, with a $1.5 \mathrm{~m}$-wide lateral wing. There was a hollow in the base of the façades, representing a $2 \mathrm{~m} \mathrm{x} 2 \mathrm{~m}$ window, from which the fire might spread outwards (Fig. 3). 


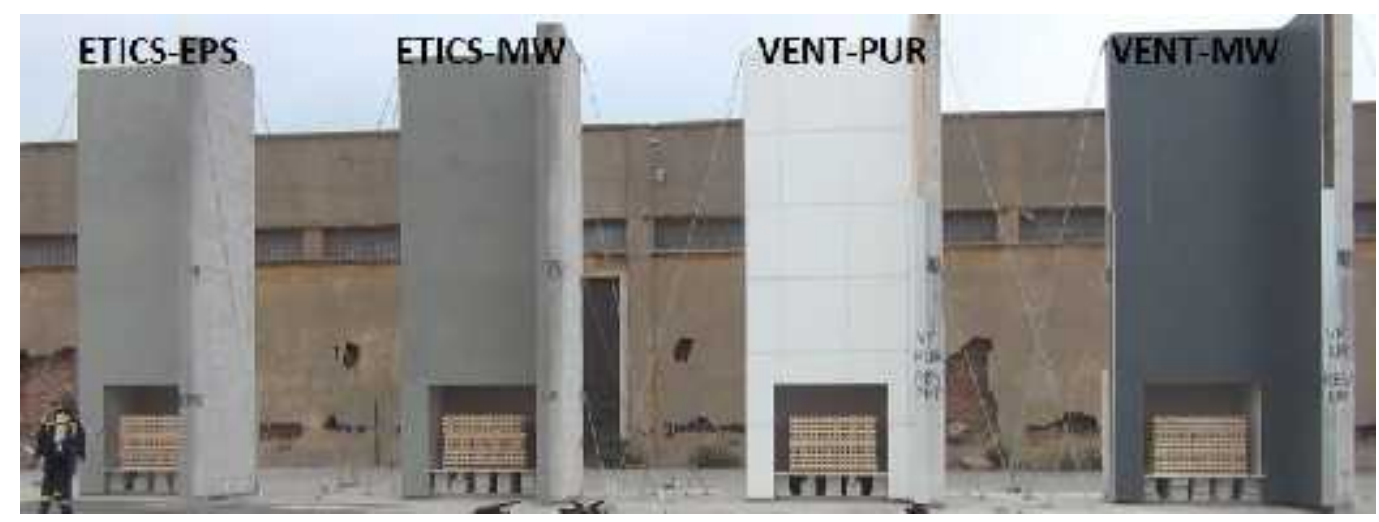

Fig. 3. Façade modules

As in the compartment fires, the façade tests were filmed using a standard video camera and an IR camera. Both cameras were located in front of the façades, capturing the four tests in the same field of view. K-type thermocouples were used to measure point-temperatures at several positions (Fig. 4) at a frequency of $1-\mathrm{Hz}$ too. In the ETICS façades, we placed centred at the façade's width, two external thermocouples at $1 \mathrm{~m}$ and $3 \mathrm{~m}$ above the lintel (named TCE1 and TCE3 respectively), and two internal sensors at these same heights, between the concrete and the insulator layers (named TCI1 and TCI3). The ventilated façades were also monitored by thermocouples placed at these same positions (TCI1, TCI3, TCE1, TCE3) and by two more thermocouples placed at $1 \mathrm{~m}$ and $3 \mathrm{~m}$ in the air chamber (TCV1, TCV3). Note that out thermocouples setting is simpler than what is stated in the BS 8414 standard.
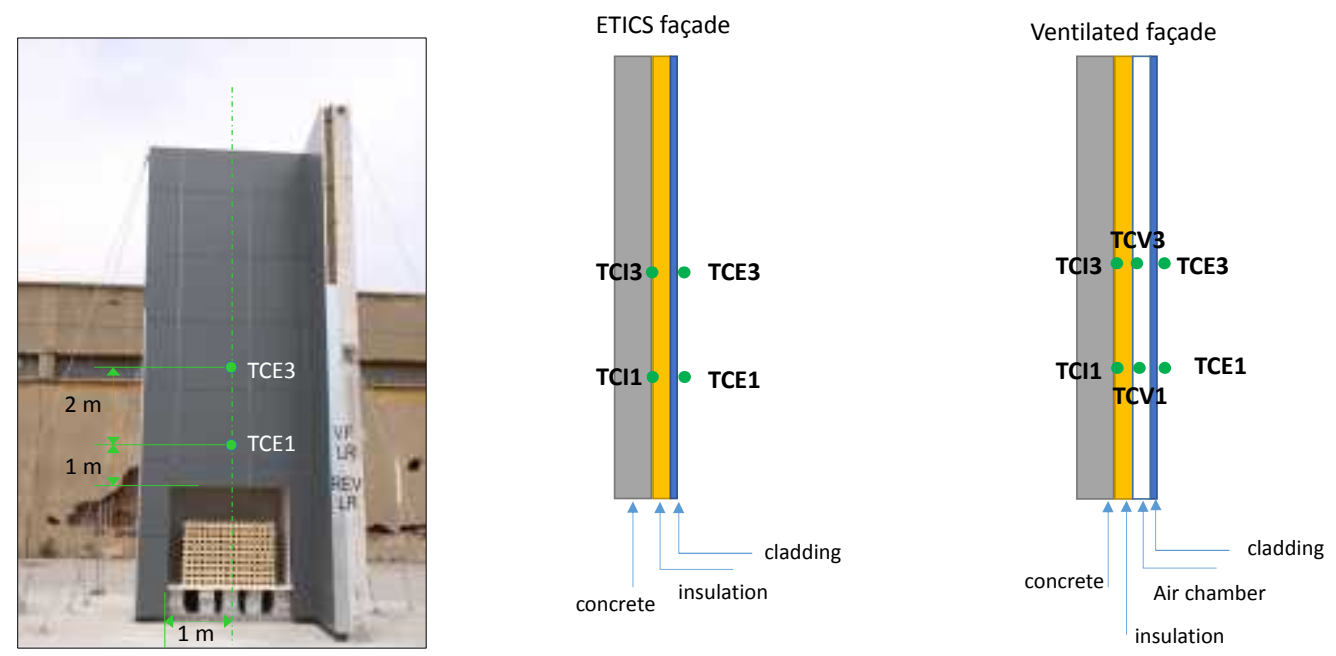

Fig. 4. Thermocouples location

\section{RESULTS AND DISCUSSION}

\subsection{Compartment tests}

Temperature evolution with time at different heights of the compartment is plotted in Fig. 5 for all the tested specimens. Concerning the PSW tests, the different behaviour of the MW module compared to the PUR one can be clearly observed (see Fig. 5 a) and b)). While in MW compartment maximum temperatures were always below 350 and flashover did not occur, the compartment insulated with PUR experienced flashover roughly 12 minutes after the beginning of the test, getting maximum temperatures around $1100^{\circ} \mathrm{C}$. In the RCT specimens, the different behaviour of the three types of insulators is depicted in Fig 5. c) and d). The PIR compartment was the one exhibiting worse performance, with maximum temperatures exceeding $1000^{\circ} \mathrm{C}-$ detected both by the 2-m height thermocouple and the IR camera- ending up to flashover. By contrast, EPS 
specimen reached maximum temperatures roughly below $600^{\circ} \mathrm{C}$ without experiencing flashover, probably due to the floor collapse during the test.

a)

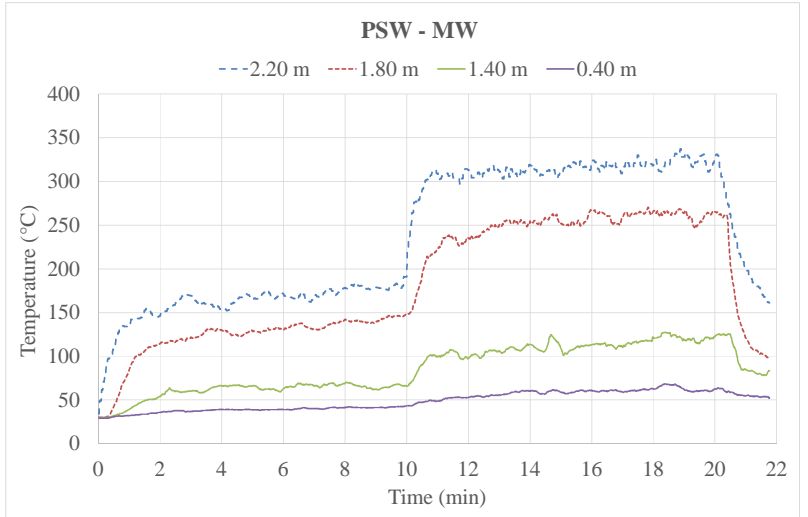

c)

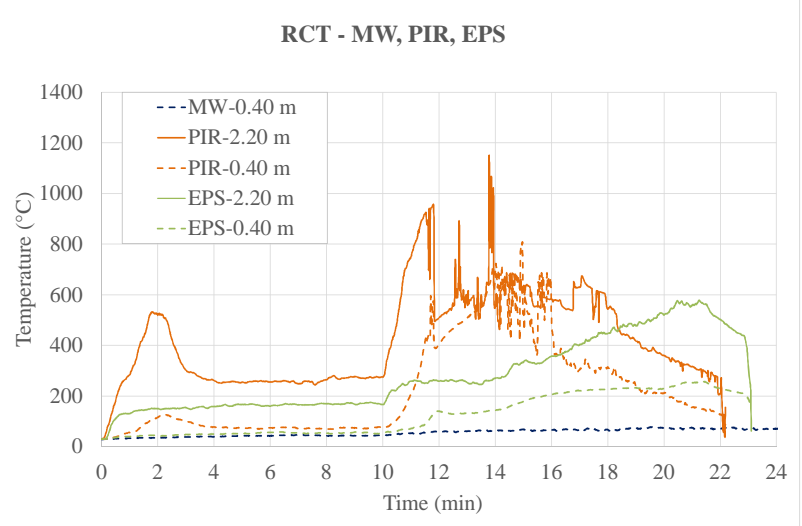

b)

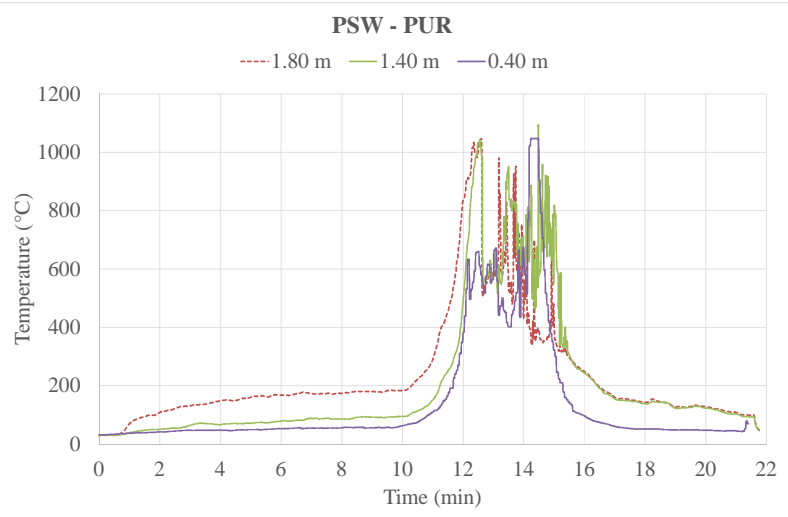

d)

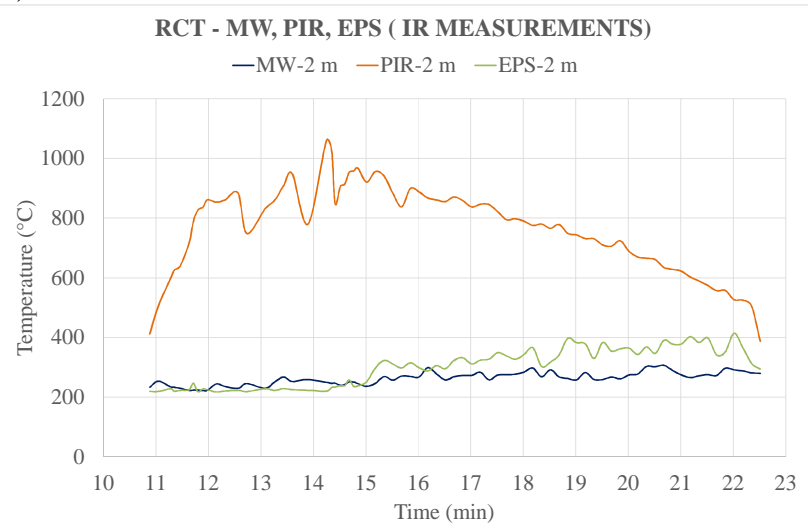

Fig. 5. a) Temperature evolution sensed by thermocouples at different heights of the PSW-MW specimen; b) temperature evolution sensed by thermocouples at different heights of the PSW-PUR specimen; c) temperature evolution comparison of the RCT-MW, PIR and EPS tests sensed by thermocouples at two different heights; d) temperature evolution comparison of the RCT-MW, PIR and EPS tests sensed by the IR camera at $2 \mathrm{~m}$ height.

\subsection{Façades tests}

Temperature evolution with time sensed by the thermocouples located at the different positions of the façades is plotted in Fig. 6 for all the tested specimens. Concerning the ETICS façades, the different behaviour of the EPS specimen compared to the MW one can be detected (see Fig. 6 a) and b)). From minute 3, it was visually evident that ETICS insulator was consumed; at this instant, TCE1 temperature started decreasing while TCI1 increased. 8 minutes later, temperatures at $1 \mathrm{~m}$ height, both external and internal, converged to $300{ }^{\circ} \mathrm{C}$ and $3 \mathrm{~m}$-temperatures did so at around 24 minutes after the beginning of the test. This might indicate a travelling EPS consumption front of around $1 / 6 \mathrm{~m} \mathrm{~min}^{-1}$. In contrast, $\mathrm{MW}$ insulator exhibited good performance, since internal temperatures (both at $1 \mathrm{~m}$ and $3 \mathrm{~m}$ ) were constant and much lower. TCE1 thermocouple in ETICSMW module experienced temperatures between $500^{\circ} \mathrm{C}$ and $750^{\circ} \mathrm{C}$ practically during the entire test, due to flame impingement.

In the ventilated façades tests, flames propagated through the air chamber from the beginning of the experiments, since all the TCV thermocouples sensed temperatures above $600{ }^{\circ} \mathrm{C}$ in both PUR and MW specimens. PUR insulator was consumed by the fire (TCI1 thermocouple registered temperatures of around $1000{ }^{\circ} \mathrm{C}$ during the second half of the test), while MW insulator layer reached temperatures of $800^{\circ} \mathrm{C}$ at $3 \mathrm{~m}$ and $650^{\circ} \mathrm{C}$ at $1 \mathrm{~m}$ without losing integrity. 

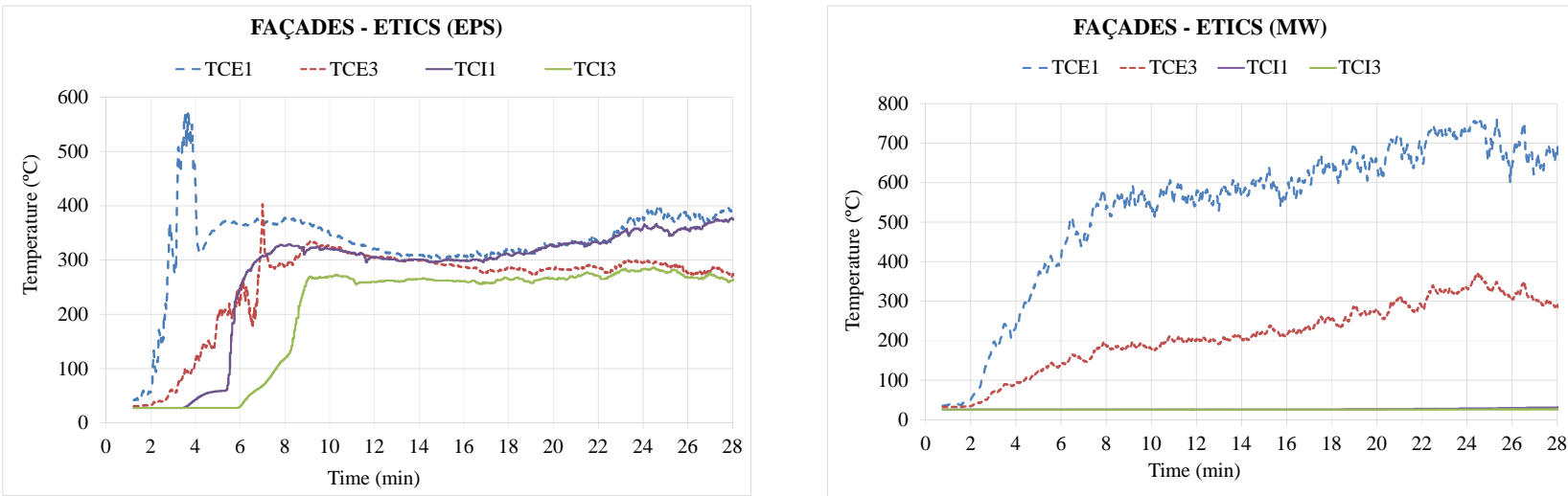

c)

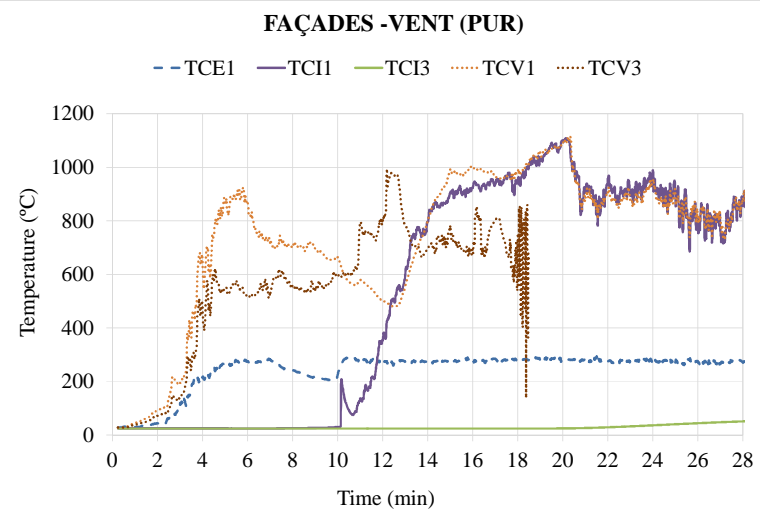

d)
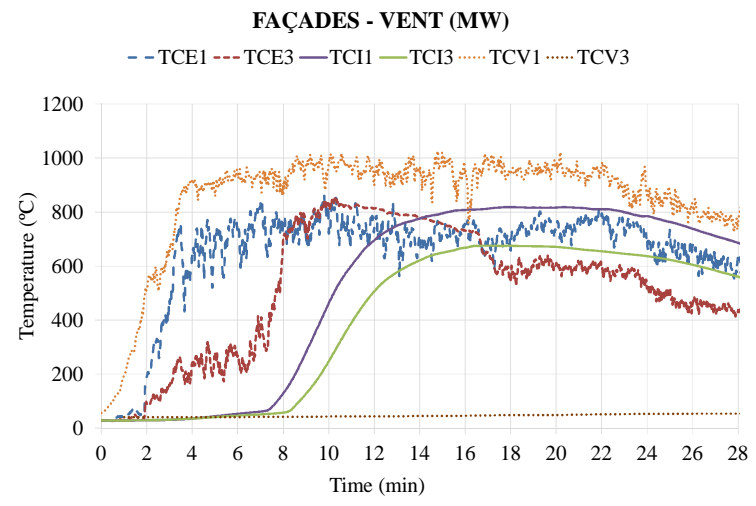

Fig. 6. Temperature evolution sensed by thermocouples of the a) ETICS-EPS b) ETICS-MW c) VENT-PUR and d) VENT-MW façade modules

\section{CONCLUSIONS}

Large scale fire experiments were undertaken with the aim of testing several insulators and building configurations currently thriving in the building sector. Our tests provided evidence (visually and through sensors measurements) that mineral wool, although reaching higher temperatures, preserves its properties in case of real fire conditions, whilst other polymeric-type insulators contribute to fire growth. Flashover in compartment fires insulated with polymeric materials and flame propagation through the air chamber of all ventilated façades were observed. This type of experimentation underlies the need of improving testing standards, by considering larger experimental scales.

\section{ACKNOWLEDGMENTS}

The authors thank the Spanish Ministry of Economy and Competitiveness (Projects $\mathrm{n}^{\circ}$. CTM201457448-R and BIA2014-52688-R), and Education, Culture and Sport (FPU Programme) and the Autonomous Government of Catalonia (Projects num. 2014-SGR-413 and 2014-SGR-01298).

\section{REFERENCES}

European Commission, 2003. Guidance paper $G$ - The European classification system for the reaction to fire performance of construction products. Brussels, May $3^{\mathrm{d}}$.

EAE, 2015. European Association for External Thermal Insulation Composite Systems. http://www.eaetics.eu/views/etics/about-etics.html (last visited July 2015).

Giraldo, M.P., Lacasta, A., Avellaneda, J. and Burgos, C. 2013. Computer-simulation study on fire behaviour in the ventilated cavity of ventilated façade systems. $1^{\text {st }}$ International Seminar for Fire Safety of Façades. MATEC Web of Conferences 9 (2013), 03002.

Netherlands Institute for Safety Nibra, 2009. Consumer fire safety: European statistics and potential fire safety measures. Project 431N8032, Final Report. The Netherlands.

The Geneva Association, 2014. World Fire Statistics. Bull. N²9, April 2014. http://www.genevaassociation.org/(last visit July 2015). 